\title{
Cultura do Código Livre e direito de acesso a uma tecnociência alternativa
}

\section{Open source culture and entitlement to access a alternative technoscience}

\author{
Marcos Alfred Brehm* \\ Felipe Mongruel ${ }^{*}$ \\ José Edmilson de Souza-Lima ${ }^{* * *}$
}

\begin{abstract}
"As ideias que constituem os alicerces da nossa visão do mundo são, na verdade, bastante simples: o mundo respeita as leis e estas vigoram universalmente. Tudo é simples e diáfano e pode expressar-se em termos matemáticos, seja mediante equações diferenciais, parciais ou ordinárias [...] Tudo é simples e diáfano, exceto, evidentemente, o mundo".
\end{abstract}

Resumo: No contexto atual de debate sobre a tecnociência, este artigo indaga acerca das possibilidades de emergência de uma tecnociência alternativa. Para tanto, tomando como referência uma metodologia centrada em técnicas bibliográficas, apresenta diversos exemplos de cooperação e de partilha desta interdisciplina induzidos pela Cultura do Código Livre (CCL). Conclui que a CCL, ao instituir uma tecnociência alternativa, consegue se projetar como possibilidade concreta de alargamento do presente e de contração do futuro para grupos excluídos pela globalização hegemônica.

Palavras-chave: Cultura do Código Livre. Direito de acesso. Tecnociência alternativa.

\begin{abstract}
Throughout the discussions of techno science, the article inquires about possible emergence of a alternative technoscience. Centered on technical literature, it presents several examples of cooperation and sharing of technoscience, induced by the Open Source Culture. Concludes that the Open Source Culture, to establish a alternative technoscience, can be projected as a concrete possibility of extending the present and the future contraction for groups excluded by hegemonic globalization.
\end{abstract}

Keywords: Open source Culture. Access rights. Alternative techno science.

Recebido em: 11/11/2011. Aceito em: 20/11/2012.

\footnotetext{
*Engenheiro eletricista (UFPR), bacharel em direito (PUC-PR) e mestrando do PPGMADE (UFPR). E- mail: marcosbrehm@gmail.com

"* Bacharel em direito (PUC-PR), pós-graduado em Ética em Perspectiva (PUC-PR). E- mail: felipe.mongruel@gmail.com

"*** Pós-Doutor em Meio Ambiente e Desenvolvimento. Pesquisador-docente do UNICURITIBA e do PPGMADE (UFPR). E- mail: zecaed@ hotmail.com
} 


\section{Introdução}

Embora este artigo possa tecer diálogos com o debate contemporâneo da tecnociência, seu objetivo é identificar os limites desta, mas igualmente suas potencialidades tomando como referências a Cultura do Código Livre (CCL) bem como as reflexões sociológicas de Boaventura de Souza Santos (2006) e as filosóficas de Hans Jonas (2006). Para os propósitos do artigo, limite e potencialidade são aqui tomados como obstáculos ou alavancas para os processos de emancipação não apenas da condição humana, mas de todas as formas de vida não só do presente como do futuro. Neste sentido, a tecnociência será apreendida como limite sempre que o seu acesso estiver restrito aos pequenos grupos; e será apreendida como potencialidade quando não apenas o acesso, mas, sobretudo, a sua coprodução estiver aberta a um coletivo mais amplo. Outro esclarecimento necessário é que este artigo não se propõe a analisar a tecnociência a partir de uma perspectiva interna, do ponto de vista técnico, mas de uma perspectiva externa, com vistas a refletir sobre seus rebatimentos nos ambientes socioculturais e biofísicos.

Para Santos (2006), a saída eficaz para os grupos marginalizados e menos favorecidos do Planeta é a cooperação, a partilha, a criação e o fortalecimento das redes de apoio mútuo e dos tecidos sociais. Os esforços recentes do jurista e sociólogo português têm se direcionado a estes objetivos. Além de lançar luzes que permitem a compreensão destes fenômenos e processos organizativos desses grupos, ao fazê-lo, esse sociólogo inspira movimentos de organização e de transformação destas realidades. Neste sentido, esta reflexão é base de inspiração para a análise da CCL, uma vez que esta também vem se constituindo e se consolidando a partir de princípios de cooperação entre desenvolvedores e usuários de softwares livres. Ao estabelecer bases para uma tecnociência alternativa, acessível aos públicos mais amplos, a CCL parece projetar-se como possibilidade concreta de expansão do presente e de contração do futuro, dessa forma abre caminhos para a conquista de um novo direito a uma tecnociência mais democrática, livre e cidadã.

Desta reflexão preliminar emerge um objetivo que este artigo propõe a enfrentar: Ao indicar limites da tecnociência comprometida com os processos de globalização hegemônica, a CCL consegue se projetar como possibilidade concreta da reivindicação acerca do alargamento do presente e da contração do futuro conforme propôs Boaventura de Souza Santos?

Em relação à metodologia, trata-se de uma pesquisa de cunho bibliográfico. Neste sentido, cada experiência colhida na bibliografia teve como propósito apresentar indicadores de uma tecnociência alternativa, com objetivo de incluir e emancipar pessoas no que se refere à produção e ao acesso às tecnologias.

Para que se possa responder a pergunta de partida, o artigo foi estruturado em sete seções, além da introdução e das considerações finais. Na Seção 1, caracteriza-se o Código Livre como instrumento capaz de transformar a ciência em conhecimento e prática social de forma simultânea. Na Seção 2, a CCL é caracterizada como um movimento centrado na partilha tanto da produção quanto do acesso às tecnologias e, neste processo, é projetada como movimento social. Na Seção 3 são apresentadas algumas aplicações práticas da CCL em atividades para além do ramo tecnológico diretamente associado a softwares. Na seção seguinte é apresentado um exemplo de plataforma tecnológica-Arduino - capaz de materializar práticas de partilha e de cooperação entre usuários e desenvolvedores de sistemas. Na Seção 5 é mostrado o conhecimento sempre como conhecimento social, como um processo contínuo de coconstrução. $\mathrm{Na}$ penúltima seção são extraídas da "guerra das ciências" lições emancipatórias, que possibilitam movimentos e processos de desmercantilização da tecnociência hegemônica e, ao mesmo tempo, abram espaços para uma tecnociência descentralizada, mais aberta e alternativa. A seção 7 articula-se a CCL ao "princípio responsabilidade", fundamento central da reflexão de Hans Jonas.

\section{A ciência como forma de conhecimento e prática social}

A ideia-força desta seção é caracterizar o Código Livre como instrumento capaz de transformar a ciência em conhecimento e prática social de forma simultânea.

O conhecimento científico é hoje forma detentora e oficialmente privilegiada 
do conhecimento entre as nações, e sua importância para a sociedade e para a vida da população é indiscutível. No entanto, constituise uma realidade que os países se dedicam à sua promoção esperando benefícios em troca deste investimento. Em toda história, as formas privilegiadas de conhecimento sempre foram alvos de discussões quanto aos seus limites, sua natureza e as benesses para a própria sociedade. Estes conhecimentos também gozaram de atribuições extracognitivas (sociais, políticas, culturais) para uma parcela da sociedade que os detêm, da mesma forma que atualmente a ciência causa impacto em toda sociedade, mesmo que não seja distribuída de forma equitativa entre ela.

No controverso terreno das discussões em torno da ciência, participam titulares de diversas áreas, filósofos, teólogos, artistas etc., e até mesmo entre cientistas há certa contenda quanto ao quem é cientista ou não. Apesar dos debates em geral se desdobrarem em duas vertentes, a da natureza e a do sentido das transformações do mundo, para os propósitos do presente artigo, inclui-se o Código Livre reivindicando o status de agente transformador, organizacional e alternativo em face das tecnologias com inclinações hegemônicas, no sentido de norma. Ao que parece, a CCL se propõe a tornar ato a função social inserida na Revolução Científica, cujo pressuposto está associado ao respeito à promoção e disponibilização do conhecimento a grupos que normalmente não têm acesso, sem discriminações de uso, possibilitando uma emergência de conhecimento à população por meio de uma racionalidade cosmopolita, capaz de expandir o presente e, em ato contínuo, contrair o futuro. Nas palavras de Santos (2006, p.779):

Os pontos de partida são três. Em primeiro lugar, a compreensão do mundo excede em muito a compreensão ocidental do mundo. Em segundo lugar, a compreensão do mundo e a forma como ela cria e legitima o poder social tem muito que ver com concepções do tempo e da temporalidade. Em terceiro lugar, a característica mais fundamental da concepção ocidental de racionalidade é o facto de, por um lado, contrair o presente e, por outro, expandir o futuro. A contração do presente, ocasionada por uma peculiar concepção de totalidade, transformou o presente num ins- tante fugidio, entrincheirado entre passado e futuro.

Esse trecho torna nítido que a ideia de associar a expansão do presente e a contração do futuro à contribuição do Código Livre. Esta combinação é aqui tomada como indicador de uma ciência como sinônimo de prática a serviço da sociedade, não apenas se restringindo a uma parcela desta. A combinação entre expansão do presente e contração do futuro irrompe como uma fonte inspiradora para questionar a ideologia em torno do culto às gerações futuras, predominante em praticamente todos os documentos e diretivas socioambientais, elaborados no Hemisfério Norte e impostos no Hemisfério Sul.

A ideologia das gerações futuras, dependendo de quem está discursando sobre ela, pode ser uma tradução de formas perversas de invisibilização de povos e de gerações presentes. Contrapondo-se a esta ideologia, as práticas fundantes de uma tecnociência participativa são um convite à aprendizagem de que os grupos que resistem às imposições da sociedade englobante são capazes de cuidar melhor do "outro". As evidências aqui apresentadas acerca da tecnociência participativa permitem apostar que alguns grupos humanos poderão se sensibilizar com a ideia de que o cuidado com o "outro" implica fortalecimento dos tecidos socioeconômico, político, ambiental, espacial, cultural e existencial. Em suma, a ideia-força deste artigo é rebater a noção de "alargamento das gerações futuras" por intermédio da perpetuação da distância entre grupos humanos. Se de um lado, os contemplados são os insiders, os "escolhidos, em geral, habitantes do Hemisfério Norte, de outro, os outsiders, em geral, habitam o Hemisfério Sul. Para estes, só resta a contração do presente, pois tudo parece apontar para um inventário de promessas vagas e muito longe de ser materializadas. Em meio a todos estes obstáculos, novas possibilidades emergem ao longo da existência societária humana, sendo a mais recente a da expansão do presente por meio de uma tecnociência livre.

\section{Cultura do Código Livre como movimento social}

A ideia-força desta seção é caracterizar a CCL como um movimento centrado na partilha 
tanto da produção quanto do acesso às tecnologias e, neste processo, a CCL projeta-se como movimento social.

Os primeiros movimentos da CCL (em inglês, Open Source Culture), embora apareçam quase sempre associados às origens do Sistema Operacional de código livre baseado no sistema UNIX' $\left(\mathrm{GNU}^{2}\right)$ - do qual o sistema operacional LINUX ${ }^{3}$ representa um ramo - da internet e da cultura "hacker", também podem ser encontrados, por exemplo, em receitas culinárias desenvolvidas e compartilhadas por diversas comunidades ao longo da história, a ponto de tomarem parte, inclusive, da poesia e literatura.

No entanto, foi no início dos processos de desenvolvimento de softwares que o movimento de código livre passou a ser mais bem definido e, consequentemente, analisado. A história do movimento remonta, assim, ao projeto GNU, lançado em setembro de 1983 por Richard Stallman. O principal motivo que levou à criação do projeto, segundo o "Manifesto GNU" escrito pelo próprio Stallman, é de que as regras de licença dos softwares proprietários (a maioria dos casos até 1980) impediam ou até proibiam a cooperação entre usuários.

A palavra "livre" no contexto do movimento de código livre não diz respeito à questão financeira, mas à liberdade de distribuição e modificação, considerada por Stallman como uma necessidade intrínseca da atividade de programação. Para ele, copiar todo ou parte de um programa é algo tão normal para um programador quanto respirar e, inclusive, tão produtivo quanto. Logo, é necessário que esta atividade seja livre, pois, caso contrário, o resultado será um processo de destruição. Segundo Stallman (1999):

\footnotetext{
1 UNIX é um sistema operacional popular em 1970, originalmente criado por Ken Thompson, Dennis Ritchie, Douglas Mcllroy e Peter Weiner, que trabalhavam nos Laboratórios Bell (Bell Labs) da AT\&T.

${ }^{2}$ Sistema Operacional de código livre baseado no sistema UNIX. O acrônimo GNU é uma espécie de "meta-acrônimo" que significa "GNU is Not Unix" e trata-se do sistema que deu origem ao LINUX.

${ }^{3}$ Sistema operacional de código livre (para que qualquer pessoa o possa utilizar, estudar, modificar e distribuir livremente de acordo com os termos da licença) cujo núcleo foi desenvolvido pelo programador finlandês Linus Torvalds.
}

Extrair dinheiro dos usuários de um programa restringindo o seu uso é destrutivo porque as restrições reduzem a quantidade de vezes e de modos em que o programa pode ser utilizado. Isto reduz a quantidade de bem-estar que a humanidade deriva do programa. Quando há uma escolha deliberada em restringir, as consequências prejudiciais são destruição deliberada. O motivo pelo qual um bom cidadão não utiliza tais meios destrutivos para se tornar mais rico é porque, se todos fizessem assim, todos nós nos tornaríamos mais pobres pela exploração mútua. Isto é ética Kantiana, ou a Regra de Ouro.

A atual definição de código livre, segundo a Open Source Initiative $\left(\mathrm{OSI}^{4}\right)$, relacionada mais diretamente ao desenvolvimento de software, está baseada em dez princípios, cujo compêndio, gerado pelos autores deste artigo a partir dos princípios que constam na íntegra no site da OSI, é elencado a seguir.

1) A distribuição deve ser livre, sem restrições à venda ou distribuição, como componente de outro programa ou não; 2) O Código fonte deve ser livre (legível e inteligível), inclusive na forma compilada; 3) Os trabalhos derivados do original devem ter distribuição sob os mesmos termos da licença original; 4) Deve-se garantir a integridade do autor do código fonte. A licença pode restringir o código fonte de ser distribuído de forma modificada apenas se a licença permitir a distribuição de arquivos de atualização (com código fonte) com o propósito de modificar o programa no momento de sua concepção; 5) Não deve haver discriminação contra pessoas ou grupos; 6) Não deve haver discriminação contra áreas de atuação, quaisquer que sejam; 7) Não há necessidade de uma licença adicional para garantir os direitos associados ao programa a todos aqueles para os quais este é redistribuído; 8) A licença não deve ser específica a um produto. Os direitos associados ao programa não devem depender que o programa seja parte de uma distribuição específica de programas; 9) A licença não deve restringir outros programas distribuídos com outro programa licenciado; 10) A licença deve ser neutra em relação ao ramo de tecnologia na qual será empregada.

\footnotetext{
${ }^{4}$ Open Source Initiative, ou Iniciativa pelo Código Aberto, é uma organização dedicada a promover o software de código aberto ou software livre.
} 
Este repertório de princípios que fundaram a CCL, todos centrados na ideia da partilha, no âmbito da teoria sociológica, especificamente na compreensão de Scherer-Warren (2006), pode ser caracterizado como um movimento social, posto que este defende que, enquanto categoria analítica, um movimento social está associado a uma ação coletiva que: envolve solidariedade em torno de interesses comuns; manifesta um conflito coletivo; e excede os limites de compatibilidade do sistema em relação à ação em pauta, exigindo que se construa um projeto de transformação. Desta forma, analisando-se os princípios, as motivações e os aspectos históricos do movimento de código livre descritos anteriormente, torna-se plenamente admissível considerar que tal iniciativa se trata de movimento social.

\section{Cultura do Código Livre: aplicações além do ramo de software}

A ideia-força desta seção é apresentar algumas aplicações práticas da CCL em atividades para além do ramo tecnológico diretamente associado aos softwares.

Uma das ideias do movimento de Código Livre pode ser resumida por uma lei epigramática publicada por Eric S. Raymond (1999, p. 30), no livro $A$ catedral e o bazar, cujo enunciado é: "Dados olhos suficientes, todos os erros são superficiais" (Given enough eyeballs, all bugs are shallow). Este adágio foi chamado de "Lei de Linus", em alusão a Linus Torvalds, criador do sistema operacional LINUX, cujo desenvolvimento foi baseado em código livre.

O princípio de que os usuários podem ser excelentes desenvolvedores se mostrou uma fórmula de sucesso no mundo dos softwares, e atualmente ganha espaço também em outros campos, por exemplo, no desenvolvimento de hardware e de ferramentas de ensino. A Tabela 1 mostra alguns exemplos de iniciativas que são baseadas na ideia de código livre, mas que possuem aplicações que vão além do ramo de software.

O primeiro exemplo de inciativa, que exibe a plataforma Arduino, será abordado mais detalhadamente na próxima seção. No segundo mostra uma iniciativa muito recente de moeda alternativa baseada em um software de código livre, com grande potencial para trazer mudan- ças substanciais no sistema bancário. O terceiro exemplo apresenta a versão espanhola do movimento open politics, cujo objetivo é a criação coletiva de preceitos de política pública mediante colaboração livre. O quarto exemplo se refere à organização Creative Commons, que tem como objetivo expandir o número de licenças de obras criativas no mundo por meio de diversos tipos de licenças gratuitas. No quinto exemplo mostra uma aplicação de caráter lúdico, a Free beer, uma receita de cerveja baseada em código livre, que, por sua vez, utiliza licença livre da Creative Commons. O último exemplo apresenta um movimento que faz uso dos preceitos do código livre objetivando a construção de cinquenta máquinas industriais que seriam essenciais para construção de uma civilização com confortos modernos. 
Tabela 1 - Exemplos de iniciativas baseadas no conceito de "open source" que não são relativas exclusivamente ao desenvolvimento de software

\begin{tabular}{|c|c|c|c|}
\hline Nome da iniciativa & Endereço do sítio & Produto resultante da iniciativa & Benefícios aos usuários \\
\hline ARDUINO & http://www.arduino.cc & $\begin{array}{l}\text { Plataforma de prototipagem } \\
\text { eletrônica baseada em hardware } \\
\text { livre, (atualmente baseada em } \\
\text { microcontrolador Atmel AVR), com } \\
\text { suporte de entrada/saída digitais e } \\
\text { analógica embutidas, que usa } \\
\text { linguagem de programação padrão, } \\
\text { essencialmente C/C++, cuja } \\
\text { compilação é executado pelo próprio } \\
\text { hardware, on-board. }\end{array}$ & $\begin{array}{l}\text { O objetivo da iniciativa é criar } \\
\text { ferramentas acessíveis, de } \\
\text { baixo custo, flexíveis e fáceis } \\
\text { de serem utilizadas por } \\
\text { artistas e amadores. }\end{array}$ \\
\hline Bit Coin & http://bitcoin.org & $\begin{array}{l}\text { Moeda digital criada em } 2009 \text { em } \\
\text { forma de programa de código aberto, } \\
\text { baseado em banco de dados } \\
\text { distribuídos pelos nós da rede, criado } \\
\text { por Satoshi Nakamoto, que é o } \\
\text { pseudônimo de alguém } \\
\text { desconhecido, mas que participou } \\
\text { dos primeiros meses dos fóruns de } \\
\text { discussão. }\end{array}$ & $\begin{array}{l}\text { Permite uma alternativa ao } \\
\text { sistema econômico mundial } \\
\text { vigente, com transações } \\
\text { instantâneas, pagamentos } \\
\text { internacionais, taxas baixas ou } \\
\text { iguais a zero, sem } \\
\text { possibilidade de haver inflação } \\
\text { da moeda. }\end{array}$ \\
\hline Open Politics & http://www.openpolitics.es & $\begin{array}{l}\text { Documento tipo "wiki", ou seja, } \\
\text { criado via software que permite } \\
\text { colaboração coletiva e possibilita } \\
\text { publicação sem revisão, que contém } \\
\text { os preceitos políticos criados } \\
\text { coletivamente a partir de princípios } \\
\text { democráticos. }\end{array}$ & $\begin{array}{l}\text { A iniciativa promove a } \\
\text { utilização dos princípios de } \\
\text { código livre por toda } \\
\text { população interessada com o } \\
\text { intuito de tornar o processo de } \\
\text { tomada de decisão mais } \\
\text { aberto, menos antagônico, e } \\
\text { mais capaz de determinar o } \\
\text { que é de real interesse público } \\
\text { com relação a questões de } \\
\text { política pública. }\end{array}$ \\
\hline $\begin{array}{l}\text { Creative Commons } \\
\text { cc creative } \\
\text { commons }\end{array}$ & http://creativecommons.org & $\begin{array}{l}\text { Licenças que permitem a cópia e } \\
\text { compartilhamento com menos } \\
\text { restrições que os métodos } \\
\text { tradicionais, através de diversos } \\
\text { tipos de licenças, conhecidas como } \\
\text { licenças Creative Commons. }\end{array}$ & $\begin{array}{l}\text { Esta organização não } \\
\text { governamental tem como } \\
\text { objetivo expandir a quantidade } \\
\text { de obras criativas disponíveis } \\
\text { através de suas licenças, } \\
\text { destinadas a qualquer pessoa } \\
\text { ou empresa interessada. }\end{array}$ \\
\hline 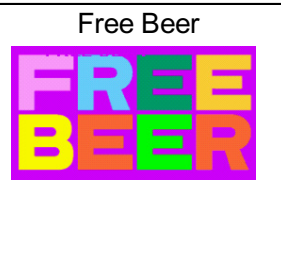 & http://www.freebeer.org & $\begin{array}{l}\text { Documento tipo "wiki", ou seja, } \\
\text { criado via software que permite } \\
\text { colaboração coletiva e possibilita } \\
\text { publicação sem revisão, que contém } \\
\text { receita de cerveja criada } \\
\text { coletivamente e de domínio público. }\end{array}$ & $\begin{array}{l}\text { Iniciativa útil para que } \\
\text { pequenos produtores de } \\
\text { cerveja (homebrewers) } \\
\text { possam criar diferentes } \\
\text { cervejas a partir da receita } \\
\text { original e discutir novos } \\
\text { processos e modificações. }\end{array}$ \\
\hline 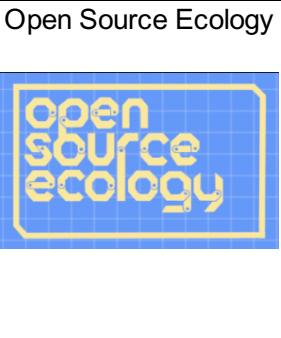 & http://opensourceecology.org & $\begin{array}{l}\text { Criação da Global Village } \\
\text { Construction Set (GVCS), uma } \\
\text { plataforma tecnológica aberta que } \\
\text { permite a fabricação das } 50 \\
\text { máquinas industriais necessárias } \\
\text { para construir uma civilização } \\
\text { pequena com confortos modernos. }\end{array}$ & $\begin{array}{l}\text { O projeto é, basicamente, } \\
\text { uma rede de troca de } \\
\text { informações voltada à } \\
\text { agricultores, engenheiros e } \\
\text { simpatizantes, com o objetivo } \\
\text { de garantir pequenas } \\
\text { civilizações humanas através } \\
\text { da viabilização da construção } \\
\text { de } 50 \text { máquinas essenciais. }\end{array}$ \\
\hline
\end{tabular}

Fonte: Os autores 


\section{Exemplo de iniciativa de movimento open source: Arduino}

A ideia-força desta seção é apresentar um exemplo de plataforma tecnológica - Arduino capaz de materializar práticas de partilha e de cooperação entre usuários e desenvolvedores de softwares.

A plataforma Arduino é uma plataforma de computação física que surgiu na Itália, em 2005, que possui como características: baixo custo, possibilidade de conexão de sensores e atuadores a sistemas lógicos digitais cuja programação se faz mediante um $\operatorname{IDE}^{5}$ (ambiente de desenvolvimento de software) de licença livre e baseado em $\mathrm{C} / \mathrm{C}++^{6}$, e uma comunicação do computador ligada à placa principal via porta $\mathrm{USB}^{7}$. O fato da plataforma Arduino possuir baixo custo (vide Tabela 2), associado à facilidade de conexão (via porta USB, com praticamente qualquer computador) e a não exigência de conhecimentos em programação de baixo nível (linguagem de máquina) abre o rol de possíveis usuários também a amadores, artistas e diversos profissionais do ensino.

A Figura 1 mostra um diagrama simplificado de funcionamento da plataforma Arduino. A placa principal possui um microcontrolador e várias entradas analógicas e entradas/saídas digitais em formato de barramento, que possibilitam uma conexão simples, rápida e eficiente de vários outros módulos, chamados de Arduino

Figura 1 - Diagrama simplificado da plataforma Arduino

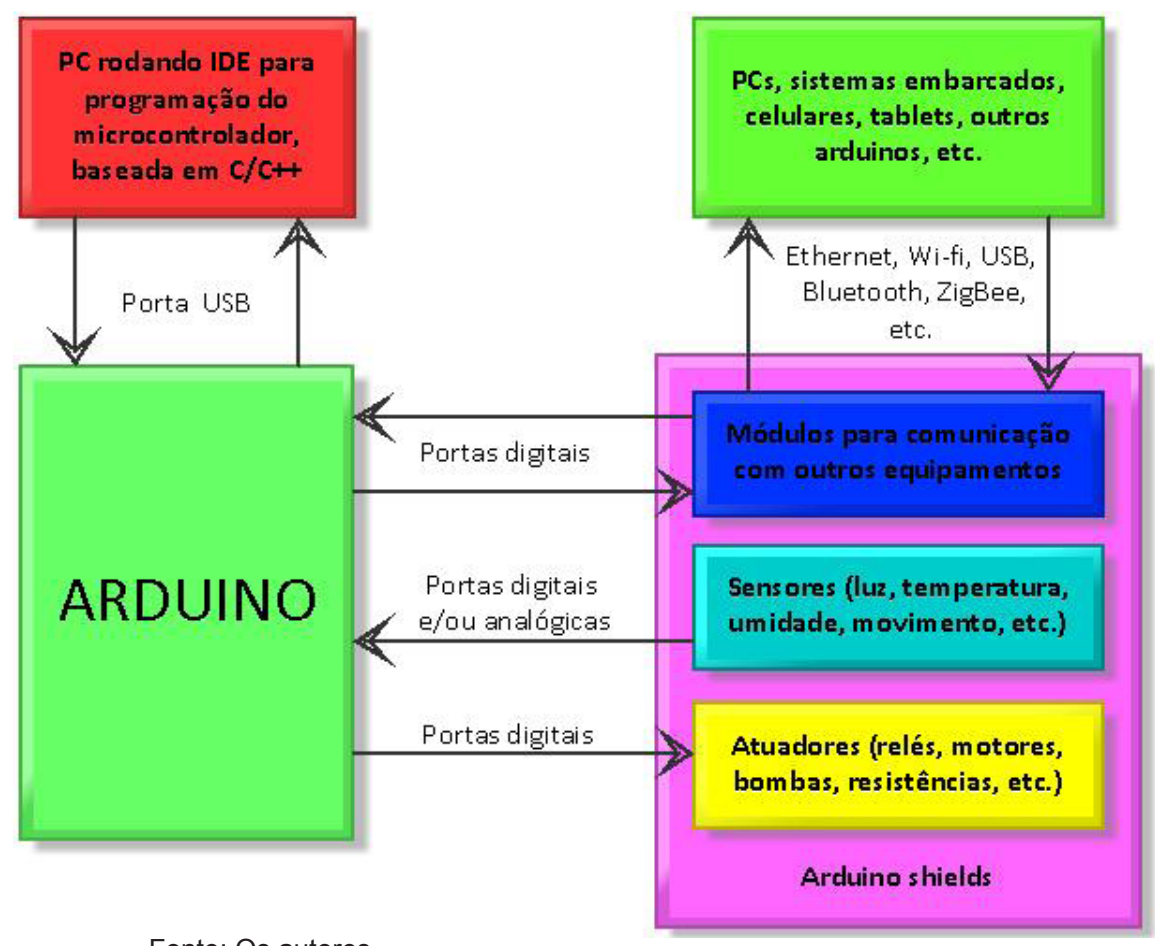

shields (vide Tabela 2), que podem ter como função a comunicação com outros equipamentos, tais quais computadores, telefones etc. ${ }^{7}$ a me-

\footnotetext{
${ }^{5}$ Integrated Development Environment, ambiente de desenvolvimento de software (para edição, compilação, testes etc.).

${ }^{6}$ Uma das linguagens de alto nível mais difundidas em cursos de Computação e Engenharia.

${ }^{7}$ Universal Serial Bus, que inclui normatização de cabos e conectores bem como protocolo de comunicação entre computadores e outros equipamentos.
}

dição de alguma variável externa (temperatura, movimento, luz etc.); ou o acionamento e controle de outras partes do sistema através de motores, bombas, relés, aquecedores etc.

O tamanho, a capacidade de processamento e o número de portas de cada placa variam a cada modelo de Arduino. Seu modelo mais difundido, conhecido como UNO, 
possui 6 entradas analógicas ${ }^{8}$ e 14 entradas/ saídas digitais $^{9}$, ligadas a um microcontrolador ${ }^{10}$ ATmega328 ${ }^{11}$, e clock ${ }^{12}$ de $16 \mathrm{MHz}$. No entanto há diversas outras versões, dentre as quais se destacam o modelo LilyPad, que usa uma placa de circuito impressa redonda com apenas $5 \mathrm{~cm}$ de diâmetro e foi desenvolvido para utilização em roupas, e o modelo DUE, mais sofisticado, utilizando um microprocessador $\mathrm{ARM}^{13}$ de 32 bits, velocidade de clock de $84 \mathrm{MHz}, 12$ entradas analógicas, 2 saídas analógicas e 54 entradas/ saídas digitais.

Quanto aos Arduino shields, que são módulos acessórios para aplicações diversas, há disponibilidade de grande variedade de modelos no mercado, inclusive disponíveis em lojas brasileiras, dos quais a Tabela 2 apresenta alguns exemplos. O primeiro exemplo é o próprio módulo principal Arduino, em sua versão mais difundida e popular, batizada como UNO; o segundo exemplo é um módulo com hardware embarcado para reconhecimento de voz; o terceiro exemplo mostra um display comum, já integrado com seis botões de comando montado em um barramento que é simplesmente encaixado no modelo UNO; o quarto exemplo apresenta um módulo de GPS ${ }^{14}$; o quinto exemplo exibe um módulo para comunicação via protocolo ether-

\footnotetext{
${ }^{8}$ Sinal analógico é um sinal contínuo cuja variação de intensidade em relação ao tempo é a representação proporcional a outra variável, normalmente representada por uma unidade física.
}

${ }^{9}$ Sinal digital é uma representação de uma sequência de valores discretos (contínuos) no tempo, definido, assim, apenas para determinados instantes de frequência.

\begin{abstract}
10 Um microcontrolador (também denominado MCU) é um chip que contém processador, memória e periféricos de entrada/saída, podendo ser incluído em diversos produtos e programado para funções específicas como um controlador embutido.
\end{abstract}

\footnotetext{
${ }^{11}$ Microcontrolador criado pela empresa ATMEL, que pertence a série megaAVR.
}

${ }^{12}$ Sinal usado por computadores, microcontroladores e sistemas afins, para coordenar e sincronizar as ações de dois ou mais circuitos eletrônicos.

\footnotetext{
${ }^{13}$ Arquitetura de processador de 32 bits utilizada principalmente em telefones celulares, tablets, calculadoras e outros sistemas embarcados, que tem como característica grande desempenho de processamento e pouco uso de energia.

${ }^{14}$ Sistema de navegação por satélite baseado na recepção de informações de relógios atômicos em órbita para cálculo de posicionamento global.
}

$n e t^{15}$ (via cabo de rede comum); o sexto exemplo apresenta um acelerômetro que mede aceleração em três eixos diferentes simultaneamente através de três saídas analógicas; e o sétimo exemplo é um módulo com quatro relés independentes, que podem ligar e desligar equipamentos elétricos através do módulo Arduino.

Desta forma, há atualmente um grande rol de ferramentas disponíveis, e, principalmente, a custos extremamente reduzidos, que podem ser facilmente utilizadas em pequena escala por qualquer cidadão, sem que haja a prévia necessidade de se saber a fundo a respeito de teoria sobre sensores, robótica ou instrumentação industrial.

Assim, em virtude da grande versatilidade do Arduino, diversos outros projetos tiveram início com a adoção deste sistema. Na Tabela 3 há diversos exemplos, como o Arducopter, projeto de quadrotor de código livre; o Ardusat, satélite de código livre; itens de alta tecnologia e de grande utilidade para pesquisadores ou pessoas comuns; ou então projetos de utilidade questionável, como - Botanicalls, que permite a "comunicação" com plantas, ou o Kickbee, que promete o mesmo mas com bebês ainda no estágio intrauterino (fetos), ambos utilizando o Twitter ${ }^{16}$.

Por fim, ainda na Tabela 3, o penúltimo exemplo apresenta o caso do Alarma Sismos, sistema baseado em Arduino e criado por um jovem de 14 anos que integrou um detector de terremotos a uma conta do Twitter e desta forma publica automática e gratuitamente mensagens com alarmes de terremoto para seus mais de 300 mil seguidores. Com um raciocínio semelhante, o último exemplo mostra a iniciativa da XIVELY (antigo COSM), uma plataforma que permite a entrada de dados e criação de aplicativos a partir de sensores conectados a vários sistemas baseados em Arduino e desenvolvidos coletivamente. Essa plataforma foi utilizada para medir e compartilhar informações de níveis de radiação no Japão depois do acidente de Fukushima mediante milhares de contadores Geiger de baixo custo, produzidos pelos próprios usuários com base em Arduino.

\footnotetext{
${ }^{15}$ Protocolo de interconexão para redes locais - Rede de Área Local (LAN) - baseada no envio de pacotes.

${ }^{16}$ Rede social e servidor para microblogging, que permite aos usuários enviar e receber atualizações pessoais de outros contatos por meio de textos de até 140 caracteres.
} 
Tabela 2 - Exemplos de módulos compatíveis com o sistema Arduino disponíveis no mercado

\begin{tabular}{|c|c|c|c|c|}
\hline Shield & & eço & Breve descrição & Imagem \\
\hline Módulo ARDUINO & $\mathrm{R} \$$ & 69,00 & $\begin{array}{l}\text { Módulo ARDUINO, modelo UNO, versão R3. } \\
\text { Trata-se do modelo mais comum de ARDUINO. }\end{array}$ & \\
\hline EasyVR & $\mathrm{R} \$$ & 199,00 & Módulo de reconhecimento de voz & \\
\hline LCD + Botões & $\mathrm{R} \$$ & 79,00 & $\begin{array}{l}\text { Display de LCD } 16 \times 2 \text { pixels e mais } 5 \text { botões } \\
\text { ligados às entradas analógicas e } 1 \text { botão de } \\
\text { reset. }\end{array}$ & \\
\hline Módulo GPS & $\mathrm{R} \$$ & 289,00 & $\begin{array}{l}\text { Módulo GPS (sistema de posicionamento } \\
\text { global) com } 66 \text { canais }\end{array}$ & \\
\hline Ethernet Shield & $\mathrm{R} \$$ & 155,00 & $\begin{array}{l}\text { Permite que uma placa Arduino conecte-se a } \\
\text { internet, fornecendo um endereço IP. }\end{array}$ & \\
\hline Acelerômetro 3 Eixos & $\mathrm{R} \$$ & 59,00 & $\begin{array}{l}\text { Mede a aceleração em três eixos diferentes, e } \\
\text { transforma em } 3 \text { saídas analógicas. }\end{array}$ & \\
\hline Shield relés & $\mathrm{R} \$$ & 75,00 & $\begin{array}{l}\text { Permite chavear até } 4 \text { equipamentos } \\
\text { independentes, tais como lâmpadas, pequenos } \\
\text { motores e aparelhos eletrônicos. }\end{array}$ & \\
\hline
\end{tabular}

Fonte: Os autores

\footnotetext{
17 Preços de referência do site www.robocore.net. Outros exemplos de sites populares com produtos ARDUINO e acessórios: www. multilogica-shop.com, dx.com, www.adafruit.com.
} 
Tabela 3 - Exemplos de projetos baseados em Arduino

\begin{tabular}{|c|c|c|c|}
\hline Nome do projeto & Endereço do sítio & $\begin{array}{c}\text { Produto resultante da } \\
\text { iniciativa }\end{array}$ & Benefícios aos usuários \\
\hline $\begin{array}{l}\text { Arducopter } \\
\text { DUCOPTER }\end{array}$ & http://www.arducopter.co.uk/ & $\begin{array}{l}\text { Projeto completo, de código } \\
\text { livre, para montagem de } \\
\text { quadrotor baseado em } \\
\text { ARDUINO. }\end{array}$ & $\begin{array}{l}\text { Possibilita a montagem de } \\
\text { um quadrotor por qualquer } \\
\text { pessoa com investimento } \\
\text { reduzido. }\end{array}$ \\
\hline $\begin{array}{l}\text { Ardusat } \\
\text { JanoSz }\end{array}$ & http://www.nanosatisfi.com & $\begin{array}{c}\text { Satélite de código livre, } \\
\text { baseado em ARDUINO e nas } \\
\text { normas CubeSat, } \\
\text { desenvolvido pela empresa } \\
\text { Nanosatisfi. }\end{array}$ & $\begin{array}{c}\text { Possibilitará o } \\
\text { desenvolvimento de } \\
\text { experiências no espaço e } \\
\text { aquisição de imagens de } \\
\text { satélite à qualquer pessoa. }\end{array}$ \\
\hline $\begin{array}{l}\text { Botanicalls } \\
\text { otanicalls } \text { ot' }^{\text {'m }}\end{array}$ & http://www.botanicalls.com/ & $\begin{array}{c}\text { Módulo com sensores } \\
\text { baseado em ARDUINO, que } \\
\text { monitora condições de } \\
\text { plantas e envia informações } \\
\text { pela internet. }\end{array}$ & $\begin{array}{c}\text { Permite a comunicação, de } \\
\text { maneira lúdica, entre pessoas } \\
\text { e plantas via twitter. }\end{array}$ \\
\hline & http://kickbee.net/ & $\begin{array}{l}\text { Sensores de movimento } \\
\text { combinados a um módulo } \\
\text { ARDUINO, que envia } \\
\text { informações via twitter } \\
\text { quando bebês se movem } \\
\text { dentro da barriga das mães. }\end{array}$ & $\begin{array}{c}\text { Permite a comunicação, de } \\
\text { maneira lúdica, com pessoas } \\
\text { que ainda não nasceram, via } \\
\text { twitter. }\end{array}$ \\
\hline Alarma Sismos & https://twitter.com/alarmasismos & $\begin{array}{l}\text { Detector de terremotos ligado } \\
\text { a um ARDUINO, que envia } \\
\text { informações pela internet. }\end{array}$ & \begin{tabular}{|c|} 
Permite seus mais de \\
300.000 seguidores \\
receberem informações \\
sobre terremotos na região do \\
Chile de forma gratuita via \\
twitter.
\end{tabular} \\
\hline ntigo & https://xively.com/ & $\begin{array}{l}\text { Plataforma que permite a } \\
\text { entrada de dados e criação } \\
\text { de aplicativos a partir de } \\
\text { diversos sensores de } \\
\text { hardware livre, baseados em } \\
\text { ARDUINO. }\end{array}$ & $\begin{array}{c}\text { Permite a utilização de dados } \\
\text { gerados por milhares de } \\
\text { pessoas em milhares de } \\
\text { localidades em tempo real, } \\
\text { como por exemplo a medição } \\
\text { dos níveis de radiação após o } \\
\text { acidente de Fukushima, } \\
\text { Japão. }\end{array}$ \\
\hline
\end{tabular}

Fonte: Os autores

\section{Todo conhecimento científico-natural é científico-social}

A ideia-força desta seção é caracterizar o conhecimento sempre como conhecimento social, como um processo contínuo de coconstrução.

A ciência moderna, em seu estudo de tecnologia e sociedade, preserva a característica de que seus resultados avançam em função da participação e da articulação dinâmica entre atores humanos, objetos, instrumentos, entidades vivas não humanas, materiais de várias espécies, recursos institucionais e financeiros. A construção da ciência se dá por interseção entre estes atores para que criem coisas que não existiam antes, e que não se restringem apenas à soma das entidades previamente ditas. De uma forma reduzida a construção entre o conhecimento e os objetos tecnológicos formam a ecologia de práticas, segundo a proposta de Stengers (1992).

Neste contexto, perde-se a validade o contexto de existência do objeto, mas ganha 
potência o teor e eficácia do objeto. Logo, há relevância em sua atuação dentro de cada ecologia de práticas e na disponibilidade de sua atuação para posteriores trabalhos.

Se "bem" construídos estiverem, estes institutos adquirem autonomia em relação às situações e aos contextos de sua construção e, logo, podem ser disponibilizados para apropriação em outros contextos e por outros atores. Por um lado, serão avaliados pelas suas consequências e pela diferença que fazem essas operações de construção e seus objetos. Por outro lado, os elementos mobilizados para esses processos de construção não podem ser manipulados arbitrariamente. Eles resistem e são avessos a essas manipulações, tornando os processos de construção em processos de equilíbrio mútuo que decorrem no tempo. A partir disso, podemos afirmar que a construção, como aqui é entendida, é sempre um processo de coconstrução.

\section{A "guerra das ciências" e a necessidade de desmercantilização da tecnociência}

A ideia-força desta seção é extrair da "guerra das ciências" lições emancipatórias, que possibilitem movimentos e processos de desmercantilização da tecnociência hegemônica e, ao mesmo tempo, abram espaços para uma tecnociência descentralizada, mais aberta e alternativa.

Na polêmica "guerra das ciências" amplamente discutida entre diversos autores, em que se enfrentam os pós-modernos e os ortodoxos, estes ainda resistem e tratam como incidente $e$ autonomia a atuação da ciência, aqueles tentam criticar e argumentar de maneira razoável a interferência e a incomensurabilidade do conhecimento científico. No entanto, historicamente percebe-se nesta área reside uma disputa em que ambas as partes buscam a exclusividade da verdade, o que acaba por priorizar argumentações que acabam por gerar mais calor que luz. Passa-se frequentemente do diálogo civilizado à troca de acusações, não raro, ao próprio ataque à integridade moral dos adversários.

De Newton até os dias de hoje, a batalha travada refere-se, mais do que apenas a uma guerra entre o velho e o novo, a um enlace sobre como produzir conhecimento válido, quais são suas autoridades, quais seus locais e onde esta- rão as orientações de ação social que podem se tornar legítimas. Mais do que a dualidade entre ciências, transparece uma guerra entre culturas.

Vale ressaltar que o intento do presente artigo não é assumir o lado de nenhuma dessas ideologias, já que de acordo com Ross (1996, p. 3) "a ciência não detém o monopólio da racionalidade", por isso, busca-se constituir apenas uma forma de conhecimento e de interação com a natureza. A ciência e a tecnologia se amalgamaram em seu desenvolvimento histórico dando origem à tecnociência, sendo esse processo o de maior desenvolvimento do capitalismo no qual dá a tecnociência o status de corresponsável pelos problemas que afligem a humanidade neste momento histórico. A persistência da miséria, da fome, da violência e das desigualdades sociais, a degradação do meio-ambiente e o esgotamento dos recursos naturais derivam não necessariamente da tecnociência, mas, em alguma medida, das formas como têm sido apropriada e gerida. Neste sentido, caberia citar o emblemático discurso do presidente do Uruguai, Pepe Mujica, a respeito dos orçamentos mundiais para guerra e para saúde na $68^{\circ}$ Assembléia da ONU, ocorrida em 2013, na cidade de Nova York:

[...] em cada minuto no mundo se gastam US\$ 2 milhões em ações militares nesta terra. Dois milhões de dólares por minuto em inteligência militar!! Em investigação médica, de todas as enfermidades que avançaram enormemente, cuja cura dá às pessoas uns anos a mais de vida, a investigação cobre apenas a quinta parte da investigação militar.

Diante dos fatos e da reflexão expostos, a visão engajada de Santos (2006) lança luzes sobre os rumos do desenvolvimento de outra tecnociência - provavelmente centrada na CCL - capaz de possibilitar a expansão do presente e a contração do futuro.

\section{O Código Livre e a ética da responsabilidade}

A ideia-força desta seção é articular a CCL ao princípio da responsabilidade, fundamento central da reflexão de Hans Jonas.

O filósofo alemão Hans Jonas sugere ao pensamento e ao comportamento humano uma nova ética. Segundo ele, a ética tradicional 
existia e acontecia apenas dentro dos limites do ser humano, não afetando a natureza e sua realidade exterior. A natureza, que cuidava de si mesma, não era objeto da responsabilidade humana. A ética era midiática e se preocupava apenas com a colocação do homem naquele espaço e tempo. Ao contrário dos antigos imperativos éticos (entre os quais o imperativo kantiano, que se constitui no exemplar "age de tal maneira que o princípio de tua ação se transforme numa lei universal"18) Jonas (2006, p. 108) propõe um novo imperativo: "Age de tal maneira que os efeitos de tua ação sejam compatíveis com a permanência de uma vida humana autêntica" ou, formulado negativamente, "não ponhas em perigo a continuidade indefinida da humanidade na Terra".

O imperativo trazido por Jonas (2006) mostra que se pode arriscar a própria vida, mas não a da humanidade. O ser humano não tem o direito de escolher a não existência de futuras gerações em função da existência da atual, ou mesmo de colocá-las em risco. Fica claro que o apontamento desse autor recai sobre uma exigência de universalização e de integridade da vida humana.

A ação humana deve levar em consideração as consequências de um futuro além de sua existência limitada, abrangendo as futuras gerações. Esse é outro ponto do pensamento de Jonas (2006) que assume um papel de não pedir nada em troca, já que o futuro não gratificará pela nossa cautela de hoje. Ao conceber, então, o seu imperativo de responsabilidade tornado em princípio, esse autor está pensando tanto no perigo da destruição física da humanidade quanto na sua morte essencial, a que advém da desconstrução e da aleatória reconstrução tecnológica do ser humano e do ambiente biofísico. Também caracteriza a existência de uma interação entre a pesquisa e o poder. Nessa nova configuração, a ciência leva a um conhecimento singular que não é mais produzido para obedecer à real função do saber durante toda a história da humanidade: a de ser incorporada nas consciências, na busca meditada e ponderada da qualidade de vida humana. $O$ imperativo tecnológico elimina a consciência e também a liberdade em proveito de um determinismo.

${ }^{18}$ KANT, I. Crítica da Razão Prática. Trad. Artur Morão. Lisboa: Ed. 70,1989
Essa separação entre os avanços científicos e a reflexão ética fez que Jonas (2006) criasse novas dimensões para a responsabilidade, defendendo a criação de uma teoria da responsabilidade. A ética da responsabilidade desse autor terá como característica combater o defeito mais forte e favorecer o lado menos beneficiado pelas circunstâncias. Nesse sentido, tal ética estará sempre ao lado dos fracos contra os fortes e aos que aspiram contra os que já possuem. Nos tempos atuais, quando se observa o ser humano e o planeta perigosamente ameaçados, a reflexão de Jonas (2006) é extremamente pertinente e esclarecedora. Só uma ética que responsabilize a todos pode cumprir o papel de apontar os valores e os fins a serem perseguidos e utilizar os meios como aquilo que realmente são, sem transformá-los em fins em si mesmos.

A ciência moderna encontra-se diante de um grande desafio de proporcionar instrumentos ao avanço de todos ou de colocar o destino de todos nas mãos dos detentores do monopólio para que estes escolham caminhos permeados por seus interesses individuais. Neste sentido, o movimento social do Código Livre, por não se sujeitar a diversas características e imposições próprias do sistema capitalista, mostra-se como uma alternativa de sucesso inegável e de grande potencial para mudanças sociais, possibilitando, de certa forma, o uso da própria tecnociência para resolver males criados por ela própria.

\section{Considerações finais}

Diante dos desafios presentes e futuros que a humanidade se vê obrigada a enfrentar, uma das possíveis aliadas é a tecnociência, desde que esteja disponível não apenas para alguns grupos sintonizados com a globalização hegemônica, mas para coletivos cada vez mais amplos. Sem querer vender ilusões, os modestos resultados apresentados aqui abrem brechas a novas reflexões acerca da produção e do acesso à tecnociência.

Neste sentido, conforme os achados da pesquisa foi demonstrado que, a despeito da força de uma tecnociência comprometida com as diversas expressões do poder hegemônico, a CCL consegue se projetar como possibilidade concreta para a reivindicação central de Sousa 
Santos (2006) acerca do alargamento do presente e da contração do futuro.

Ao transformar a tecnociência em instrumento de emancipação e de conquista de direitos negados ou dificultados por práticas hegemônicas, a CCL ajuda a instituir novas bases para a cidadania e age em participação ao ideário coletivo e público, talvez até em tentativa de dirimir a desigualdade social em todos os sentidos, como pela técnica. Nesta qualquer pessoa passa a ter acesso às diferentes ferramentas para alcançar novos resultados, posto que por exemplo o conhecimento acerca da linguagem de programação de baixo nível (que utiliza e trabalha diretamente com as instruções do processador) não é mais uma exigência sine qua non, já que esta nova geração de sistemas costuma trabaIhar diretamente com linguagens de alto nível (que possuem nível de abstração relativamente elevado, longe do código de máquina e mais próximo à linguagem humana), como verificado no exemplo da iniciativa do projeto Arduino, que utiliza uma linguagem baseada em $\mathrm{C}++$. Além da técnica, outra possibilidade que a CCL mostra na tentativa de diminuir a desigualdade é pela participação econômica difundida por esta plataforma, pois torna-se economicamente viável a pequenos grupos sistemas de controle e automação cada vez mais complexos e de grande desempenho de processamento.

Ademais, a CCL reserva-se à seara do direito autoral, este agente de direito moral tão intransferível quanto à autoria, contudo reservado aos direitos de cópia, no entanto na CCL percebe-se mais uma alternativa para apaziguamento do distanciamento social causado por aqueles que pretendem apenas que as populações atendam aos apelos da técnica de forma puramente consumista, posto que permite a participação de maior parte da população nestas obras dos novos tempos.

Este artigo pode, assim, inspirar estudos futuros diretamente associados à constituição de sujeitos coletivos de direitos, à luz da CCL. Com tais novos estudos o campo jurídico terá lugar privilegiado no debate envolvendo tecnociência, cidadania e emancipação.

Por último, soma-se às exposições a valorização de uma sublime característica humana, o poder de criação. Afinal, esta característica tem como âmago um agente capacitor transfor- mador de realidades que tem a possibilidade de criar o homem como agente causador de novos homens, por sua vez, cada vez mais mutáveis e com maiores capacidades de adequação aos seus limites, já que tempos exigentes e coercitivos demandam novas capacidades de pluralização às demais esferas da sociedade, de forma a colocar a ciência, a técnica ou qualquer outro meio de linguagem dos dias atuais, unidos ou não, em favor, pelo e para o ser humano.

\section{Referências}

ARDUINO. Arduino Build Process. Disponível em: <http://arduino.cc/en/Hacking/BuildProcess >. Acesso em: 05 dez. 2012.

BITCOIN. An open source P2P digital currency. Disponível em: <http://bitcoin.org>. Acesso em: 10 abr. 2013.

CREATIVE COMMONS. Disponível em: <http:// creativecommons.org>. Acesso em: 05 dez. 2012.

FREE BEER. Disponível em: <http://www.freebeer. org >. Acesso em: 05 dez. 2012.

GNU OPERATING SYSTEM. GNU Manifest. Disponível em: <http://www.gnu.org>. Acesso em: 05 dez. 2012.

GOLDENFELD, N. \& KADANOFF, L. Simple Lessons from Complexity. Science, 284, 87-89, 1999

LEIA A ÍNTEGRA do discurso de José Mujica na ONU. Presidente uruguaio criticou o capitalismo e o individualismo em discurso que empolgou nas Nações Unidas. 2013. Disponível em: <http://zh.clicrbs. com.br/rs/noticias/noticia/2013/09/leia-a-integrado-discurso-de-jose-mujica-na-onu-4281650.html>. Acesso em: 02 jun. 2014.

JONAS, H. O Princípio responsabilidade. Ensaio de uma ética para a civilização tecnológica. Rio de Janeiro: Contraponto Editora; Editora PUC-Rio, 2006.

OPEN POLITICS. Disponível em <http://www. openpolitics.es>. Acesso em: 05 dez. 2012.

OPEN SOURCE ECOLOGY. Disponível em: <http:// opensourceecology.org>. Acesso em: 05 dez. 2012.

OPEN SOURCE INICIATIVE. The Open Source Definition. Disponível em: <http://opensource.org/ osd>. Acesso em: 05 dez. 2012.

RAYMOND, E. S. The Cathedral and The Bazaar. 1. ed. Sebastopol: O'Reilly and Associates, 1999. 
ROSS, A. (Org.) Science wars. Durham, Carolina do Norte: Duke University Press, 1996.

SANTOS, B. de S. Conhecimento prudente para uma vida decente: um discurso sobre as ciências revisitado. 2. ed. São Paulo: Cortez, 2006.

SCHERER-WARREN, I. Das mobilizações às redes de movimentos sociais. Sociedade e Estado, Brasília, v. 21, n. 1, 2006.

STALLMAN, R. M. GNU Manifest. 1999. Disponível em: <http://www.gnu.org>. Acesso em: 05 dez. 2012.

STENGERS, I. "Les 'nouvelles sciences', modele ou défi?” Review, Paris, v. 15, n. 1, p. 9 